Mitsuhiro Abe', Kenji Tsushima², Keiichiro Yoshioka', Masashi Sakayori, Kenichi Suzuki', Yasutaka Hirasawa', Takeshi Kawasaki', Jun Ikari' ${ }^{1}$, Jiro Terada' ${ }^{1}$, Koichiro Tatsumi ${ }^{1}$

'Department of Respirology, Graduate School of Medicine, Chiba University, Chiba, Japan

${ }^{2}$ Department of Pulmonary Medicine, International University of Health and Welfare, School of Medicine, Chiba, Japan

\title{
The Gender-Age-Physiology system as a prognostic model in patients with idiopathic pulmonary fibrosis treated with nintedanib: a longitudinal cohort study
}

\begin{abstract}
Introduction: The Gender-Age-Physiology (GAP) system is a tool for predicting prognosis in patients with idiopathic pulmonary fibrosis (IPF). Yet, to date, the GAP system has not been evaluated in patients with IPF who received nintedanib.

Material and methods: This single-center retrospective study included 89 patients with IPF who received nintedanib for at least 3 months. All-cause mortality was set as the end point. Clinical parameters, including the GAP stage, were statistically analyzed for risk factors leading to mortality using the Cox proportional hazard model.

Results: The median follow-up was 16.4 months (range 3.7-37.4 months), during which 23 patients died. Univariate analysis revealed that the GAP stage (hazard ratio [HR] 3.00, 95\% confidence interval [Cl] 1.52-5.92, p = 0.0014) and $\mathrm{PaO}_{2}(\mathrm{HR} 0.95,95 \%$ $\mathrm{Cl} 0.92-0.98, \mathrm{p}=0.0063$ ) were significant prognostic factors. Multivariate analysis revealed that the GAP stage was a significant prognostic factor (HR 2.26, 95\% $\mathrm{Cl} 1.07-4.78, \mathrm{p}=0.031$ ). Log-rank analysis revealed that there were no significant differences in "Gender" ( $p=0.47)$ and "Age" ( $p=0.18)$ factors. However, there were significant differences in "Physiology" factors (\% of forced vital capacity, $p=0.018 ; \%$ of diffusing capacity of lung carbon monoxide, $p<0.001)$. The cumulative incidences of mortality at 1 and 2 years were as follows: GAP I: $5.1 \%$ and $6.8 \%$; GAP II: $9.5 \%$ and $29.3 \%$; and GAP III: $18.9 \%$ and $84.2 \%$.

Conclusions: The GAP system is useful as a prognostic tool in patients with IPF who have been treated with nintedanib.
\end{abstract}

Key words: diffusing capacity of lung carbon monoxide, forced vital capacity, GAP stage, idiopathic pulmonary fibrosis, nintedanib Adv Respir Med. 2020; 88: 369-376

\section{Introduction}

Idiopathic pulmonary fibrosis (IPF) is a chronic progressive interstitial pneumonia [1]. IPF exhibits a poor prognosis similar to many types of cancers, with an average survival time of 2-3 years after diagnosis [2-4]. Pulmonary function tests are important in the evaluation of the severity of IPF $[1,4]$. In pulmonary function testing, the forced vital capacity (FVC) and the diffusion capacity of lung carbon monoxide $\left(\mathrm{D}_{\mathrm{LCO}}\right)$ have been identified as important prognostic factors in patients with $\operatorname{IPF}[2,5,6]$.

Nintedanib is a tyrosine-kinase inhibitor that targets vascular endothelial growth factor receptors, fibroblast growth factor receptors, and platelet-derived growth factor receptors [7, 8]. In the most recent international clinical practice guidelines, nintedanib received a conditional recommendation for the treatment of IPF [9]. It should be noted that although nintedanib was useful in patients with severe IPF who did not meet the eligibility criteria for clinical trials of nintedanib (INPULSIS-1/2 trial [10]), we previously reported that the prognosis of these patients was worse [11].

An accurate evaluation of a patient's clinical severity combined with a theory regarding prognosis are both very important clinical issues in determining appropriate treatment. Several prognostic

Address for correspondence: Mitsuhiro Abe, Department of Respirology, Graduate School of Medicine, Chiba University, Chiba, Japan; e-mail: mthrsgnm@chiba-u.jp DOI: 10.5603/ARM.a2020.0137

Received: 13.02 .2020

Copyright (C) 2020 PTChP

ISSN 2451-4934 
factors for IPF have been reported including male gender [12], elderly age [13], \%FVC at baseline [13-15], and $\% \mathrm{D}_{\mathrm{LCO}}$ at baseline [14]. In addition, serum biomarkers (surfactant proteins $\mathrm{A}$ and $\mathrm{D}$ [16], C-C motif chemokine ligand 18 [15], and matrix metalloproteinase collagen fragments [17]) and gene polymorphisms (MUC5B promoter polymorphism [18]) have been reported as prognostic factors. However, as these biomarkers are difficult to measure in general hospitals, they are not always used as prognostic factors in clinical practice.

The Gender-Age-Physiology (GAP) system has been reported as a simple and useful tool for the prediction of prognosis in patients with IPF in several nationwide IPF registries (e.g., Germany, Australia, and South Korea) [19-22]. However, these registries include many patients who were registered prior to the increased use of antifibrotic drugs. Since 2015, antifibrotic agents (e.g., pirfenidone and nintedanib) have been recommended as treatments for IPF [9].

Recently, the GAP system was evaluated as a prognostic model in patients with IPF treated with pirfenidone [23-25]. However, to date, the GAP system has not been evaluated in patients with IPF who received other recommended antifibrotic agents such as nintedanib. Therefore, in this study, we retrospectively examined whether the GAP system is useful as a prognostic model in patients with IPF who have received nintedanib.

\section{Materials and methods}

This single-center, retrospective study was performed in accordance with the amended Declaration of Helsinki. The research protocol was approved by the Human Ethics Committee of Chiba University Hospital (approval number: 3481). We obtained informed consent with an option to opt out.

\section{Patients}

Overall, 142 consecutive patients received nintedanib in the Chiba University Hospital between November 2015 and December 2018. Patients who did not have IPF $(n=31)$, patients with lung cancer at the start of nintedanib $(\mathrm{n}=8)$, and patients who received nintedanib for acute exacerbations $(n=3)$ were excluded. Of the remaining 100 patients, 11 patients were excluded because they discontinued treatment within 3 months of starting therapy with nintedanib. Ultimately, 89 patients with IPF were enrolled (Figure 1). IPF was diagnosed based on the American Thoracic Society/European Respiratory Society Thoracic

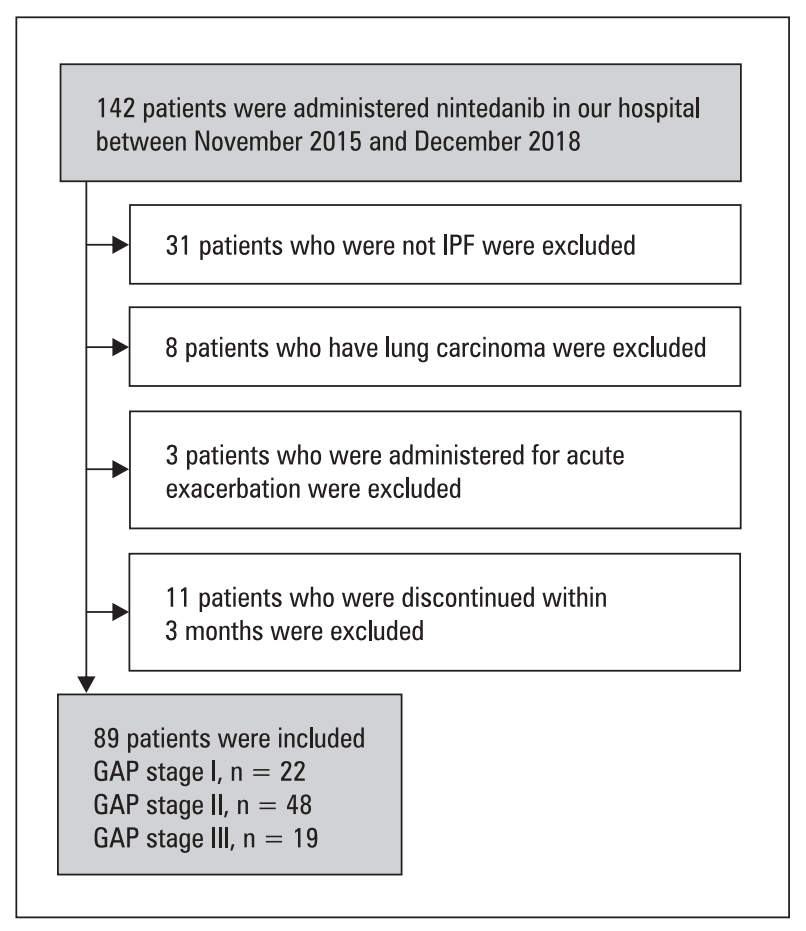

Figure 1. Study flow chart. In total, 124 patients received nintedanib in our hospital between November 2015 and December 2018. Patients who did not have IPF ( $n=26)$, with lung cancer at the start of nintedanib treatment $(\mathrm{n}=6)$, and who received nintedanib for acute exacerbation stage $(n=3)$ were excluded. Of the remaining 92 patients, 12 were excluded because they discontinued treatment within 3 months of nintedanib administration. Ultimately, 82 patients with IPF were enrolled (GAP stage I, $n=20$; GAP stage II, $n=45$; GAP stage III, $\mathrm{n}=17$ ). GAP — Gender-Age-Physiology stage; IPF — idiopathic pulmonary fibrosis

Association/Japanese Respiratory Society (JRS)/ Latin American Thoracic Association IPF guidelines from 2018 [26].

\section{GAP system}

The GAP score was calculated according to the report by Ley et al. [19]: gender (female, 0 points; male, 1 point), age ( $\leq 60$ years, 0 points; 61-65 years, 1 point; $>65,2$ points), \%FVC (> 75\%, 0 points; 50-75, 1 point; < 50, 2 points), and $\% \mathrm{D}_{\mathrm{LCO}}(>55 \%, 0 ; 36-55,1$ point; $\leq 35,2$ points; cannot obtain $\mathrm{D}_{\mathrm{LCO}}, 3$ points). The GAP stage was determined based on the total GAP score: stage I ( $0-3$ points), stage II ( $4-5$ points), and stage III (6-8 points).

\section{JRS severity staging system}

The JRS severity staging system consists of the combination of two known prognostic variables which are resting arterial partial pressure of oxygen $\left(\mathrm{PaO}_{2}\right)$ and peripheral capillary oxygen saturation $\left(\mathrm{SpO}_{2}\right)$ in the 6-minute walk test (6MWT) 
[27]. The present severity staging system for IPF defines $\mathrm{PaO}_{2} \geq 80$ Torr at rest as stage I, 70-79 Torr as stage II, $60-69$ Torr as stage III, and $<60$ Torr as stage IV. If the $\mathrm{SpO}_{2}$ at the end of 6MWT is $<90 \%$, then the severity should be increased by one stage for patients with stage II or III.

\section{Statistical analysis}

The clinical data regarding continuous variables are expressed as the mean \pm standard deviation. The categorical variables are given as percentages. The Cox proportional hazard model analysis was used to identify significant factors for predicting patient mortality. Kaplan-Meier survival curves and log-rank tests were used to compare patient survival according to GAP stages. The level of significance [p value $(p)<0.05$ ] was adopted as statistically significant. All statistical analyses were performed using the EZR software package (Saitama Medical Center, Jichi Medical University, Saitama, Japan) [28] and the graphical user interface for R ( $R$ version 3.2.0, The R Foundation for Statistical Computing, Vienna, Austria).

\section{Results}

The baseline characteristics of the included patients (GAP I, $\mathrm{n}=22$; GAP II, $\mathrm{n}=48$; GAP III, $\mathrm{n}=19$ ) are shown in Table 1 . The median duration of follow-up time, which started following 3 months of treatment, was 16.4 months (range 3.7-37.4 months). Twenty-three deaths (25\%) were observed during the follow-up time (GAP I, $\mathrm{n}=2$ [9\%]; GAP II, $\mathrm{n}=11$ [22\%]; GAP III, $\mathrm{n}$ $=10[52 \%])$. The causes of death are shown in Table 2. Ten patients died of chronic pulmonary failure and eight patients died due to an acute exacerbation of disease.

The log-rank test result revealed a significant difference in mortality among the three groups (GAP I, II, and III; $p=0.0013$; Figure 2). The cumulative incidences of mortality at 1 and 2 years were as follows: GAP I, $5.1 \%$ and $6.8 \%$; GAP II, $9.5 \%$ and $29.3 \%$; and GAP III, $18.9 \%$ and $84.2 \%$.

The survival curves drawn for each of the four factors comprising the GAP system (gender, age, $\% F V C$, and $\% D_{\text {LCO }}$ ) are shown in Figures $3-6$. There were no significant differences between male and female patients $(\mathrm{p}=0.47$; Figure 3 ), or among the three age groups ( $p=0.18$; Figure $4)$. There was a significant difference among the three groups in \%FVC ( $p=0.018$; Figure 5$)$ and $\% \mathrm{D}_{\text {LCO }}(\mathrm{p}<0.001$; Figure 6$)$.

The log-rank test result also revealed a significant difference in the survival of patients who were not admitted for hospital care among the

\section{Table 1. Baseline characteristics of 89 included patients}

\begin{tabular}{|c|c|c|c|c|}
\hline & Total $(n=89)$ & GAP I (n= 22) & GAP II $(n=48)$ & GAP III (n = 19) \\
\hline Age & $71.3 \pm 6.2$ & $70.3 \pm 5.4$ & $71.6 \pm 7.0$ & $71.5 \pm 4.6$ \\
\hline Male, n (\%) & $68(76 \%)$ & $15(68 \%)$ & $39(81 \%)$ & $14(73 \%)$ \\
\hline Smoker, n (\%) & $68(76 \%)$ & $15(68 \%)$ & $38(79 \%)$ & $15(78 \%)$ \\
\hline $\mathrm{BMI}\left(\mathrm{kg} / \mathrm{m}^{2}\right)$ & $23.8 \pm 4.0$ & $23.9 \pm 4.0$ & $23.9 \pm 4.1$ & $23.4 \pm 3.7$ \\
\hline Severity staging system in JRS (I/II/III/IV) & 29 / 4 / 26 / 30 & $13 / 1 / 5 / 3$ & 14 / 2 / $17 / 15$ & $2 / 1 / 4 / 12$ \\
\hline UIP pattern in HRCT & $66(74 \%)$ & $13(59 \%)$ & $37(77 \%)$ & $16(84 \%)$ \\
\hline Pre-treatment with PFD & $32(35 \%)$ & $4(18 \%)$ & $15(31 \%)$ & $13(68 \%)$ \\
\hline Long-term home oxygen therapy & $23(25 \%)$ & $3(13 \%)$ & $9(18 \%)$ & $11(57 \%)$ \\
\hline $\mathrm{PaO}_{2}(\mathrm{~mm} \mathrm{Hg})$ & $73 \pm 13$ & $81 \pm 13$ & $73 \pm 12$ & $63 \pm 11$ \\
\hline Minimum $\mathrm{SpO}_{2}$ by $6 \mathrm{MWT}(\%)$ & $80 \pm 9$ & $83 \pm 10$ & $80 \pm 7$ & $75 \pm 12$ \\
\hline $\mathrm{KL}-6(\mathrm{U} / \mathrm{mL})$ & $1421 \pm 1114$ & $1252 \pm 953$ & $1323 \pm 1106$ & $1889 \pm 1242$ \\
\hline $\mathrm{FVC}(\mathrm{mL})$ & $2172 \pm 802$ & $2735 \pm 833$ & $2129 \pm 706$ & $1601 \pm 544$ \\
\hline$\% F V C(\%)$ & $67 \pm 19$ & $86 \pm 17$ & $64 \pm 14$ & $50 \pm 11$ \\
\hline$\%_{\text {DLCO }}(\%)$ & $56 \pm 21$ & $71 \pm 9$ & $54 \pm 22$ & $32 \pm 7$ \\
\hline Follow-up duration, median [range] (month) & $16.4[3.7-37.4]$ & $16.5[4.5-33.9]$ & $18.1[3.7-37.4]$ & $12.5[4.0-36.0]$ \\
\hline Death, n (\%) & $23(25 \%)$ & $2(9 \%)$ & $11(22 \%)$ & $10(52 \%)$ \\
\hline
\end{tabular}


Table 2. Cause of death

\begin{tabular}{lcccc}
\hline & Total $(\mathbf{n}=\mathbf{8 9})$ & GAP I (n= 22) & GAP II (n=4 8) & GAP III (n= 19) \\
\hline Death, $\mathrm{n}(\%)$ & $23(25 \%)$ & $2(9 \%)$ & $11(22 \%)$ & $10(52 \%)$ \\
Chronic pulmonary failure & 10 & 0 & 6 & 4 \\
Acute exacerbation & 8 & 0 & 4 & 4 \\
Lung cancer & 2 & 1 & 1 & 0 \\
Pneumonia & 3 & 1 & 0 & 2 \\
\hline
\end{tabular}

GAP — Gender-Age-Physiology

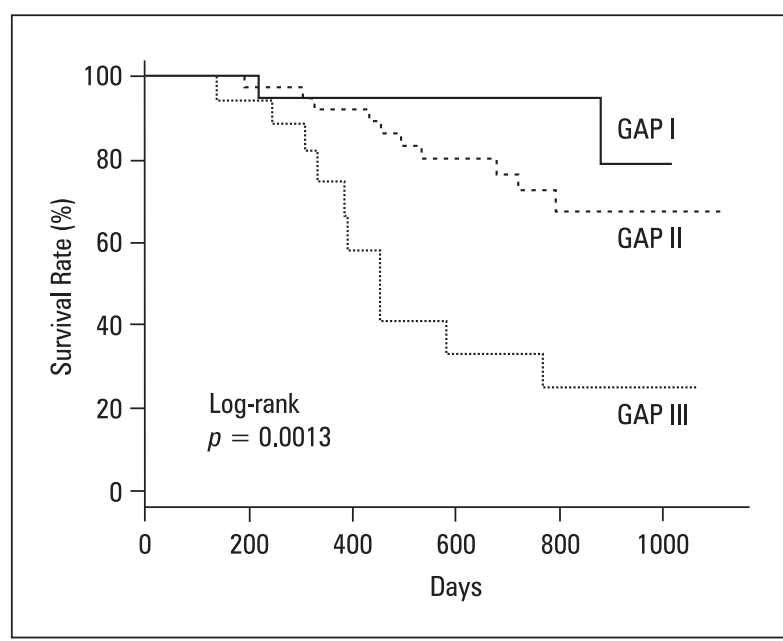

Figure 2. Survival curves of GAP stages I, II, and III. The log-rank test result reveals a significant difference in mortality among the three groups (GAP I, II, and III) ( $p=0.0013$ ). GAP — Gender-Age-Physiology stage.

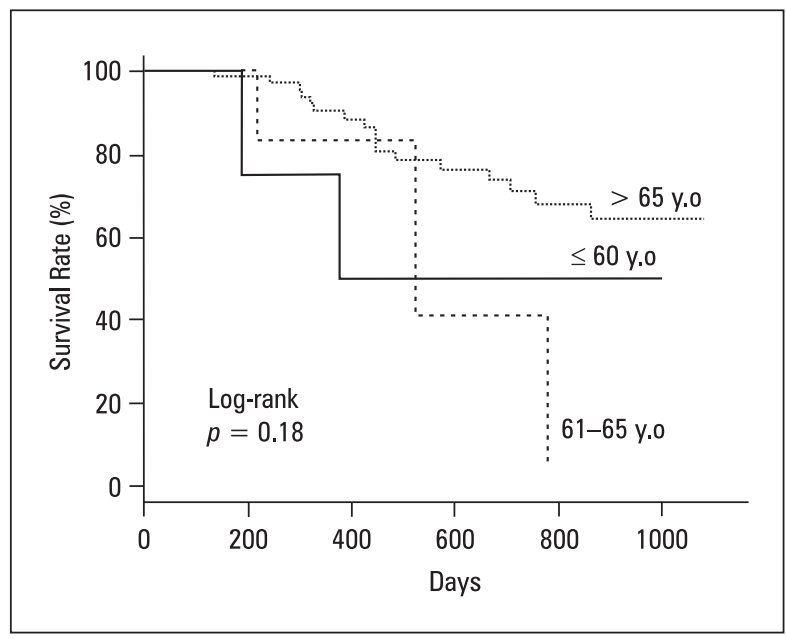

Figure 4. Survival curves of the three age groups. The log-rank test result reveals no significant difference among the three age groups $(p=0.14)$. Y.o. - years old

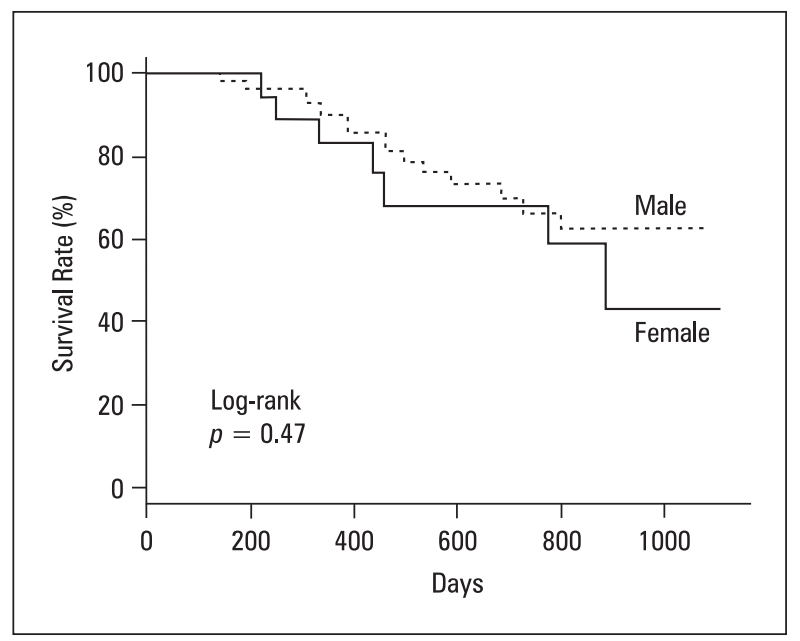

Figure 3. Survival curves between male and female patients. The logrank test result reveals no significant difference between male and female patients $(p=0.40)$

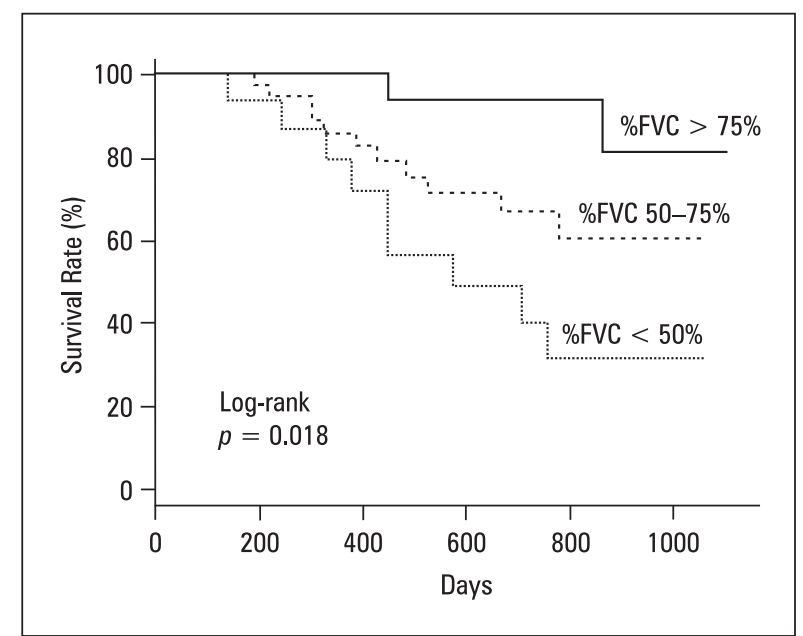

Figure 5. Survival curves of the three groups of \%FVC. The log-rank test result reveals a significant difference among the three groups of $\% \mathrm{FVC}(p=0.015)$. \%FV — percentage of forced vital capacity 


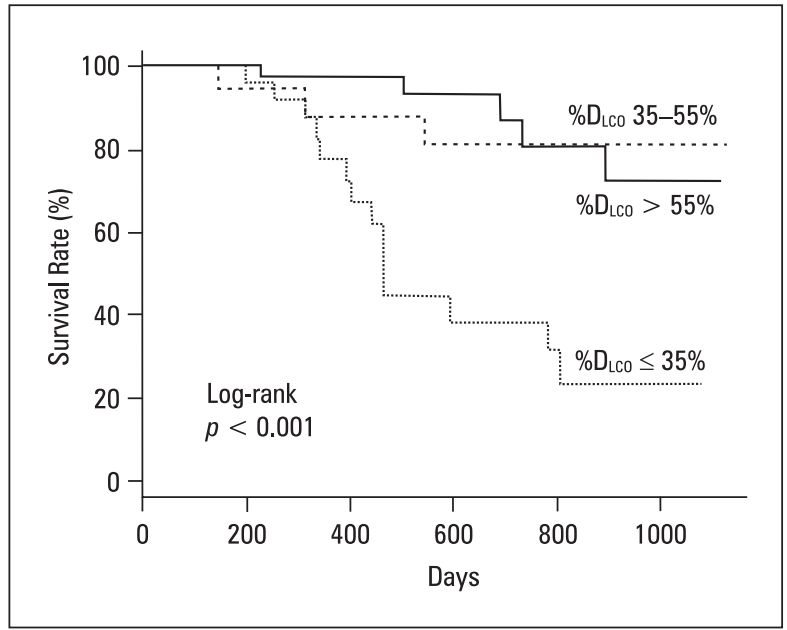

Figure 6. Survival curves of the three groups of $\% D_{L C 0}$. The log-rank test result reveals a significant difference among the three groups of $\% D_{L c 0}(p<0.001) . \% D_{L C O}$, diffusing capacity of lung carbon monoxide

three groups (GAP I, II, and III; $p=0.033$; Figure 7). The cumulative incidence of admission or death at 1 and 2 years were as follows: GAP I, 5.1\% and $6.8 \%$; GAP II, $14.9 \%$ and $34.6 \%$; and GAP III, $46.8 \%$ and $91.5 \%$.

Univariate analysis revealed that the GAP stage [hazard ratio (HR) 3.00, 95\% confidence interval (CI) 1.52-5.92, $\mathrm{p}=0.0014], \mathrm{PaO}_{2}(\mathrm{HR}$ $0.95,95 \%$ CI $0.92-0.98, p=0.0063$ ), and longterm home oxygen therapy (HR 2.72, 95\% CI $1.17-6.28, p=0.018)$ were significant risk factors (Table 3). Additionally, the \%FVC (HR 0.96, 95\% CI $0.93-0.98, \mathrm{p}=0.0042)$ and the $\% \mathrm{D}_{\text {LCO }}(\mathrm{HR} 0.93$, 95\% CI $0.90-0.97, \mathrm{p}<0.001$ ), which constitute the GAP stage, were demonstrated as significant risk factors. Multivariate analysis with the GAP stage, $\mathrm{PaO}_{2}$, and body mass index (BMI), which had low p-values in the univariate analysis, showed that the GAP stage (HR 2.26, 95\% CI $1.07-4.78, \mathrm{p}=0.031$ ) and BMI (HR 0.89, 95\% CI $0.80-0.99, p=0.048$ ) were significant prognostic factors (Table 3).

\section{Discussion}

To the best of our knowledge, this is the first study to demonstrate that the GAP system, which is a prognostic model for patients with IPF, also has prognostic value in patients with IPF that had been treated with the antifibrotic agent nintedanib (Figure 2). In Japan, the JRS severity system is a classification system based on $\mathrm{PaO}_{2}$ and the lowest $\mathrm{SpO}_{2}$ in the 6MWT. In the present study, we found that while $\mathrm{PaO}_{2}$ was a significant prognos-

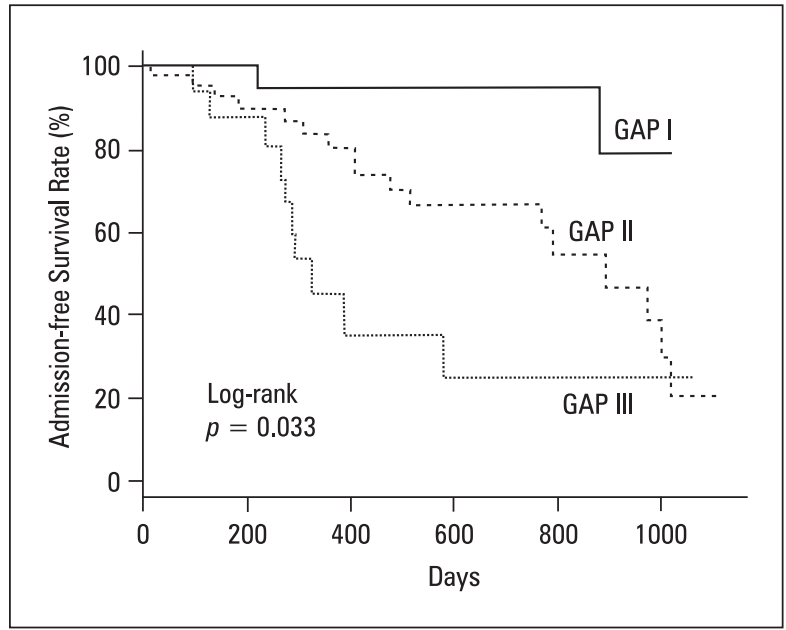

Figure 7. Admission-free survival curves of GAP stages I, II, and III. The log-rank test result reveals a significant difference in admission free survival time among the three groups (GAP I, II, and III) ( $p=$ 0.033). GAP — Gender-Age-Physiology stage

tic factor in univariate analysis, the JRS severity system was not (Table 3). Moreover, multivariate analysis revealed that the GAP system and BMI were also significant prognostic factors. The GAP system has been reported as a simple and useful tool for the prediction of prognosis in patients with IPF [19], However, the use of the GAP system as a prognostic model was proposed before the widespread use of antifibrotic drugs for IPF treatment. Therefore, it was potentially less useful in the context of antifibrotic drug treatment. Recently, the GAP system has been validated as a prognostic model for patients with IPF receiving the antifibrotic drug pirfenidone [23-25]. Our current results confirm these findings and suggest that the GAP system is also an appropriate prognostic model for patients with IPF receiving the antifibrotic drug nintedanib.

In this study, \%FVC was the strongest prognostic factor among the four items evaluated in the GAP system. The effects of age and gender were weaker than those of $\% \mathrm{FVC}$ and $\% \mathrm{D}_{\mathrm{LCO}}$ (Figures 3-6). We found no significant differences in sex (HR 0.72, 95\% CI 0.29-1.76, p = 0.47) in the univariate analysis, although male patients tended to have a better prognosis (Figure 3). In the original report of the GAP system by Ley et al. [19], sex had a lower impact on prognosis compared with other factors. Although mortality due to IPF was initially reported to be higher in men [12], a recent study by Song et al. [29] found that among 380 patients with IPF, survival time was nearly equivalent between male (46.6 months) and female (45.0 months) patients (Chi-squared 
Table 3. Univariate and multivariate analysis of survival

\begin{tabular}{|c|c|c|c|c|c|c|}
\hline & \multicolumn{3}{|c|}{ Univariate analysis } & \multicolumn{3}{|c|}{ Multivariate analysis } \\
\hline & HR & $95 \% \mathrm{Cl}$ & p-value & HR & $95 \% \mathrm{Cl}$ & p-value \\
\hline Age & 0.98 & $0.93-1.04$ & 0.63 & & & \\
\hline Male & 0.72 & $0.29-1.76$ & 0.47 & & & \\
\hline Smoker & 0.96 & $0.35-2.60$ & 0.94 & & & \\
\hline BMI & 0.90 & $0.82-1.00$ & 0.056 & 0.89 & $0.80-0.99$ & 0.048 \\
\hline Severity staging system in JRS & 1.37 & $0.95-1.99$ & 0.091 & & & \\
\hline GAP stage & 3.00 & $1.52-5.92$ & 0.0014 & 2.26 & $1.07-4.78$ & 0.031 \\
\hline UIP pattern in HRCT & 2.30 & $0.68-7.77$ & 0.17 & & & \\
\hline Pre-treatment with PFD & 1.47 & $0.88-2.45$ & 0.13 & & & \\
\hline Long-term home oxygen therapy & 2.50 & $1.10-5.68$ & 0.027 & & & \\
\hline $\mathrm{PaO}_{2}$ & 0.95 & $0.92-0.98$ & 0.0063 & 0.97 & $0.93-1.00$ & 0.11 \\
\hline Minimum $\mathrm{SpO}_{2}$ by $6 \mathrm{MWT}$ & 0.96 & $0.93-1.00$ & 0.061 & & & \\
\hline KL-6 & 1.00 & $0.99-1.00$ & 0.91 & & & \\
\hline FVC & 0.50 & $0.27-0.90$ & 0.022 & & & \\
\hline$\% F V C$ & 0.96 & $0.93-0.98$ & 0.0042 & & & \\
\hline$\% D_{\text {Lco }}$ & 0.95 & $0.92-0.98$ & 0.0023 & & & \\
\hline
\end{tabular}

test, $\mathrm{p}=0.887$ ). These findings are consistent with the outcome of our study and together suggest that the administration of nintedanib does not affect the relationship between gender and prognosis.

In the present study, elderly people ( $>65$ years) did not have a worse prognosis than young people ( $\leq 60$ years). While Song et al. [29] reported that younger patients ( $<50$ years) tended to have a good prognosis compared to that of elderly patients ( $>75$ years), the difference was not significant (Kolmogorov-Smirnov test, $\mathrm{p}=0.268$ ). One potential reason for this difference is due to nintedanib's high frequency of side effects (e.g., diarrhea, anorexia, liver injury) [10]. Elderly patients with a poor general condition might not have received nintedanib due to their attending physician's preferences. This may have affected the assessment of differences in prognosis by age.

In this study, the cumulative incidences of mortality at 1 and 2 years were as follows: GAP I, 5.1\% and 6.8\%; GAP II, 9.5\% and 29.3\%; and GAP III, $18.9 \%$ and $84.2 \%$, respectively. These results are similar to those reported by Harari et al. [25] in their study of patients who received pirfenidone (GAP I, 8.4\% and 17.2\%; GAP II, 17.6\% and $34.2 \%$; and GAP III $28.3 \%$ and $51.2 \%$, respec- tively) thus indicating the validity of the present study. Together, these findings also suggest that the therapeutic effects obtained by nintedanib and pirfenidone might be similar.

Notably, our results showed that patients with GAP stage III have an extremely poor prognosis. Therefore, it is desirable to start treatment of these patients immediately. However, our results indicate that for patients with IPF with GAP stage I/II, it is also important to start early treatment with antifibrotic drugs. In the original report of the GAP system by Ley et al., [19] the cumulative incidences of mortality at 1 and 2 years were as follows: GAP I, 5.6\% and 10.9\%; GAP II, $16.2 \%$ and 29.9\%; and GAP III 39.2\% and $62.8 \%$. Although obtaining a direct comparison between the studies is difficult due to differences in patient background, the overall mortality rate in the present study tended to be better than that reported by Ley et al. [19]. However, it should be noted that the 2-year mortality rate for GAP III patients was higher in the present study. The long-term effects of nintedanib in patients with advanced IPF are unknown and should be clarified in further studies.

Our study revealed that the GAP system is not only a prognostic model, but also an appropriate predictive model of survival in non-admitted pa- 
tients with IPF who were receiving the antifibrotic drug nintedanib (Figure 7).

This study had some limitations. Firstly, the study had a retrospective, single-center design with a small sample size. Secondly, the median follow-up duration was short. Therefore, in the future, it will be necessary to demonstrate the usefulness of the GAP system in patients receiving antifibrotic drugs in a large-scale, nationwide, prospective study.

\section{Conclusions}

The GAP stage is useful as a prognostic tool in patients with IPF who have been treated with nintedanib. The physiological parameters of the GAP system (\%FVC and $\% \mathrm{D}_{\mathrm{LCO}}$ ) are of particular importance with regard to patient prognosis.

\section{Acknowledgements}

We would like to thankEditage (www.editage.jp) for English language editing.

\section{Authors' contributions}

MA and KTs analyzed and interpreted the patient data regarding idiopathic pulmonary fibrosis treated with nintedanib. MA was a major contributor to the writing of the manuscript. All authors read and approved the final manuscript.

\section{Competing interests}

MA, KTs, and KTa report receipt of personal fees from Boehringer Ingelheim Japan.

\section{Funding}

This work was supported by the Japanese Society for the Promotion of Science KAKENHI (Grant Number JP19K20727).

\section{References:}

1. Raghu G, Collard HR, Egan JJ, et al. An official ATS/ERS/ JRS/ALAT statement: idiopathic pulmonary fibrosis: evidence-based guidelines for diagnosis and management. Am J Respir Crit Care Med. 2011; 183(6): 788-824, doi: 10.1164/ rccm.2009-040GL, indexed in Pubmed: 21471066.

2. Vancheri C, Failla M, Crimi N, et al. Idiopathic pulmonary fibrosis: a disease with similarities and links to cancer biology. Eur Respir J. 2010; 35(3): 496-504, doi: 10.1183/09031936.00077309, indexed in Pubmed: 20190329.

3. Olson AL, Swigris JJ, Lezotte DC, et al. Mortality from pulmonary fibrosis increased in the United States from 1992 to 2003. Am J Respir Crit Care Med. 2007; 176(3): 277-284, doi: 10.1164/ rccm.200701-0440C, indexed in Pubmed: 17478620.

4. Natsuizaka M, Chiba H, Kuronuma K, et al. Epidemiologic survey of Japanese patients with idiopathic pulmonary fibrosis and investigation of ethnic differences. Am J Respir Crit Care Med. 2014; 190(7): 773-779, doi: 10.1164/rccm.201403-05660C, indexed in Pubmed: 25162152.

5. du Bois RM, Nathan SD, Richeldi L, et al. Idiopathic pulmonary fibrosis: lung function is a clinically meaningful endpoint for phase III trials. Am J Respir Crit Care Med. 2012; 186(8): 712-715, doi: 10.1164/rccm.201206-1010PP, indexed in Pubmed: 22798316.

6. Karimi-Shah BA, Chowdhury BA. Forced vital capacity in idiopathic pulmonary fibrosis--FDA review of pirfenidone and nintedanib. N Engl J Med. 2015; 372(13): 1189-1191, doi: 10.1056/NEJMp1500526, indexed in Pubmed: 25806913.

7. Hilberg F, Roth GJ, Krssak M, et al. BIBF 1120: triple angiokinase inhibitor with sustained receptor blockade and good antitumor efficacy. Cancer Res. 2008; 68(12): 4774-4782, doi: 10.1158/0008-5472.CAN-07-6307, indexed in Pubmed: 18559524.

8. Wollin L, Wex E, Pautsch A, et al. Mode of action of nintedanib in the treatment of idiopathic pulmonary fibrosis. Eur Respir J. 2015; 45(5): 1434-1445, doi: 10.1183/09031936.00174914, indexed in Pubmed: 25745043.

9. Raghu G, Rochwerg B, Zhang Y, et al. An Official ATS/ERS/ JRS/ALAT Clinical Practice Guideline: Treatment of Idiopathic Pulmonary Fibrosis. An Update of the 2011 Clinical Practice Guideline. Am J Respir Crit Care Med. 2015; 192(2): e3-19, doi: 10.1164/rccm.201506-1063ST, indexed in Pubmed: 26177183.

10. Richeldi L, du Bois RM, Raghu G, et al. Efficacy and safety of nintedanib in idiopathic pulmonary fibrosis. N Engl J Med. 2014; 370(22): 2071-2082, doi: 10.1056/NEJMoa1402584, indexed in Pubmed: 24836310.

11. Abe M, Tsushima K, Tatsumi K, et al. Utility of nintedanib for severe idiopathic pulmonary fibrosis: a single-center retrospective study. Drug Des Devel Ther. 2018; 12: 3369-3375, doi: 10.2147/DDDT.S179427, indexed in Pubmed: 30349191.

12. Johnston I, Britton J, Kinnear W, et al. Rising mortality from cryptogenic fibrosing alveolitis. BMJ. 1990; 301(6759): 1017-1021, doi: 10.1136/bmj.301.6759.1017, indexed in Pubmed: 2249048.

13. King TE, Tooze JA, Schwarz MI, et al. Predicting survival in idiopathic pulmonary fibrosis: scoring system and survival model. Am J Respir Crit Care Med. 2001; 164(7): 1171-1181, doi: 10.1164/ajrccm.164.7.2003140, indexed in Pubmed: 11673205.

14. Nathan SD, Shlobin OA, Weir N, et al. Long-term course and prognosis of idiopathic pulmonary fibrosis in the new millennium. Chest. 2011; 140(1): 221-229, doi: 10.1378/chest.10-2572, indexed in Pubmed: 21729893.

15. Neighbors M, Cabanski CR, Ramalingam TR, et al. Prognostic and predictive biomarkers for patients with idiopathic pulmonary fibrosis treated with pirfenidone: post-hoc assessment of the CAPACITY and ASCEND trials. Lancet Respir Med. 2018; 6(8): 615-626, doi: 10.1016/S2213-2600(18)30185-1, indexed in Pubmed: 30072107.

16. Wang K, Ju Q, Cao J, et al. Impact of serum SP-A and SP-D levels on comparison and prognosis of idiopathic pulmonary fibrosis: A systematic review and meta-analysis. Medicine (Baltimore). 2017; 96(23): e7083, doi: 10.1097/MD.0000000000007083, indexed in Pubmed: 28591049.

17. Jenkins RG, Simpson JK, Saini G, et al. Longitudinal change in collagen degradation biomarkers in idiopathic pulmonary fibrosis: an analysis from the prospective, multicentre PROFILE study. Lancet Respir Med. 2015; 3(6): 462-472, doi: 10.1016/ S2213-2600(15)00048-X, indexed in Pubmed: 25770676.

18. Peljto AL, Zhang Y, Fingerlin TE, et al. Association between the MUC5B promoter polymorphism and survival in patients with idiopathic pulmonary fibrosis. JAMA. 2013; 309(21): 2232-2239, doi: 10.1001/jama.2013.5827, indexed in Pubmed: 23695349.

19. Ley B, Ryerson CJ, Vittinghoff E, et al. A multidimensional index and staging system for idiopathic pulmonary fibrosis. Ann Intern Med. 2012; 156(10): 684-691, doi: 10.7326/00034819-156-10-201205150-00004, indexed in Pubmed: 22586007.

20. Kreuter M, Swigris J, Pittrow D, et al. Management of patients with idiopathic pulmonary fibrosis in clinical practice: the INSIGHTS-IPF registry. Eur Respir J. 2015; 46(1): 186-196, doi: 10.1183/09031936.00217614, indexed in Pubmed: 25837040.

21. Jo HE, Glaspole I, Grainge C, et al. Baseline characteristics of idiopathic pulmonary fibrosis: analysis from the Australian 
Idiopathic Pulmonary Fibrosis Registry. Eur Respir J. 2017; 49(2), doi: 10.1183/13993003.01592-2016, indexed in Pubmed: 28232409.

22. Lee SH, Park JS, Kim SY, et al. Comparison of CPI and GAP models in patients with idiopathic pulmonary fibrosis: a nationwide cohort study. Sci Rep. 2018; 8(1): 4784, doi: 10.1038 s41598-018-23073-3, indexed in Pubmed: 29555917.

23. Albera C, Costabel U, Fagan EA, et al. Efficacy of pirfenidone in patients with idiopathic pulmonary fibrosis with more preserved lung function. Eur Respir J. 2016; 48(3): 843-851, doi: 10.1183/13993003.01966-2015, indexed in Pubmed: 27471208.

24. Hosein K, Le J, Mura M. Assessing the therapeutic response to pirfenidone in idiopathic pulmonary fibrosis: can we do better than with forced vital capacity alone? Lung. 2017; 195(1): 101-105, doi: 10.1007/s00408-016-9963-3, indexed in Pubmed: 27858160.

25. Harari S, Caminati A, Confalonieri M, et al. The prognostic role of Gender-Age-Physiology system in idiopathic pulmonary fibrosis patients treated with pirfenidone. Clin Respir J. 2019; 13(3): 166-173, doi: 10.1111/cri.12999, indexed in Pubmed: 30675755.
26. Raghu G, Remy-Jardin M, Myers JL, et al. Diagnosis of idiopathic pulmonary fibrosis. An official ATS/ERS/JRS/ALAT clinical practice guideline. Am J Respir Crit Care Med. 2018; 198(5): e44-e68, doi: 10.1164/rccm.201807-1255ST, indexed in Pubmed: 30168753.

27. Nukiwa T, Abe T, Yaekashiwa M. A revised clinical staging classification of idiopathic interstitial pneumonia. The Annual Report by Study Group of Ministry of Health and Welfare for Diffuse Lung Disease. Diffuse Lung Disease Research Group from the Ministry of Health, Labor and Welfare of Japanese Government. 1999: 36-41.

28. Kanda Y. Investigation of the freely available easy-to-use software 'EZR' for medical statistics. Bone Marrow Transplant. 2013; 48(3): 452-458, doi: 10.1038/bmt.2012.244, indexed in Pubmed: 23208313.

29. Song H, Sun D, Ban C, et al. Independent clinical factors relevant to prognosis of patients with idiopathic pulmonary fibrosis. Med Sci Monit. 2019; 25: 4193-4201, doi: 10.12659 MSM.914725, indexed in Pubmed: 31166938. 